\title{
RELATÓRIO DE SUSTENTABILIDADE OU RELATO INTEGRADO DAS EMPRESAS LISTADAS NA BM\&FBOVESPA: FATORES DETERMINANTES DE DIVULGAÇÃO
}

\author{
Veronica Silva Ricardo \\ Mestranda em Ciências Contábeis \\ Universidade Federal do Espírito Santo - UFES \\ veronica.ricardo@hotmail.com \\ Sabrina Sobrinho Barcellos \\ Mestranda em Ciências Contábeis \\ Universidade Federal do Espírito Santo - UFES \\ sobrinho.sabrina@hotmail.com \\ Patrícia Maria Bortolon \\ Doutora em Administração de Empresas \\ Universidade Federal do Espírito Santo - UFES \\ p.m.bortolon@gmail.com
}

\begin{abstract}
RESUMO
Essa pesquisa objetivou identificar quais variáveis são capazes de influenciar na probabilidade de publicação do relatório de sustentabilidade ou relato integrado pelas empresas listadas na BM\&Fbovespa nos anos de 2011 a 2014. Esse estudo analisou 386 companhias. Utilizou-se os modelos logit com dados empilhados e erros padrão robustos clusterizados e logit em painel com efeitos aleatórios para testar as hipóteses de que tamanho, rentabilidade, nível de governança corporativa, participação no Índice de Sustentabilidade Empresarial (ISE) e setor de atuação das empresas com atividades de alto grau de impacto ambiental influenciam positivamente na probabilidade de divulgação de um dos relatórios citados. Como resultados, observou-se que o tamanho e a participação da empresa na carteira do ISE impactam, de forma positiva, sua probabilidade de publicação de um dos relatórios. Por outro lado, as variáveis "rentabilidade", "nível de governança corporativa" e "setor" não tiveram resultados significativos para a amostra selecionada.
\end{abstract}

Palavras-chave: Disclosure ambiental; Relato integrado; Relatório de sustentabilidade; Responsabilidade social corporativa.

\section{SUSTAINABILITY REPORT OR INTEGRATED REPORTING OF LISTED COMPANIES IN BM\&FBOVESPA: DETERMINANTFACTORS OFDISCLOSURE}

\section{ABSTRACT}

This research aimed to identify which variables can influence the probability of disclosure of the sustainability report or integrated reporting by companies listed on the BM\&FBOVESPA in the years 2011 to 2014 . The study analyzed 386 companies. We used the logit models with stacked data and standard clustered robust errors and logit panel with random effects to test the hypothesis that the size, profitability, the level of corporate governance, participation in the Corporate Sustainability Index (ISE) and the sector of activity of companies with a high degree of environmental impact activities influence positively the likelihood of disclosure of the mentioned reports. As a result, it was observed that the size and the company's participation in the ISE portfolio impact positively the likelihood of disclosure of the reports. On the other hand, the variables "profitability", "level of corporate governance" and "sector" did not have significant results for the selected sample.

Key words: Corporate social responsibility; Environmental disclosure; Integrated reporting; Sustainability report. 


\section{INTRODUÇÃO}

As questões ambientais estão cada vez mais em evidência na atualidade. Hackston e Milne (1996), Ribeiro (2010), Tinoco e Kraemer (2011) e Dias (2011) concordam ao afirmarem que os efeitos causados pelo mau uso dos recursos naturais fizeram aumentar a preocupação não só das empresas, mas também da população e dos investidores que têm demonstrado uma "consciência ecológica" ao adquirir produtos e serviços. As empresas, por sua vez, buscam se adaptar a essa nova demanda aderindo a práticas corretas e justas em âmbito socioambiental e que possuam viabilidade econômica (Alencar, Simoni, Fiorelli \& Angelis-Neto, 2015). Nesse contexto, segundo Kraemer, Behling, Rebelo e Goede (2013), as organizações deverão considerar a variável ambiental em seus cenários e na tomada de decisão, mantendo, assim, uma postura de responsabilidade ambiental. Essa atitude além de danificar menos o meio ambiente, ainda pode ser uma forma de diminuir custos para a empresa (Ribeiro, 2010).

Tal postura contribui para o desenvolvimento sustentável que pode ser definido, de acordo com a Comissão Mundial sobre Meio Ambiente (1991, p.9), como "[...]aquele que satisfaz as necessidades do presente sem comprometer a capacidade de as gerações futuras atenderem também às suas[...]", ou seja, o alinhamento do desenvolvimento econômico com o uso consciente dos recursos naturais como forma de garantir a manutenção desses recursos no longo prazo. Silva, De Jesus, Morigi e De Souza (2015, p. 482) afirmam que "[...]o atendimento das questões sociais pela empresa conduz ao caminho da sustentabilidade, e é por meio das ações socialmente corretas que se possibilita o alcance da credibilidade social corporativa".

Uma forma de atender essas questões é a divulgação de relatórios de sustentabilidade ou do Relato Integrado que procura incentivar as boas práticas de transparência e gestão das empresas. Esses relatórios buscam identificar, mensurar e divulgar o desempenho socioambiental das mesmas. Para incentivar a publicação desses relatórios, houve a recomendação da BM\&FBovespa, feita por meio de Comunicado Externo, para que as empresas listadas indiquem, a partir de 2012, referente ao ano calendário 2011, se publicam Relatório de Sustentabilidade ou Relato Integrado e onde está disponível ou em caso negativo, explicar por que não o fazem. Essa iniciativa facilitou o acesso à informação e incentiva a adesão progressiva à prática.

Nesse contexto, esta pesquisa busca responder a seguinte questão: Quais fatores influenciam na probabilidade de publicação do Relatório de Sustentabilidade ou Relato Integrado pelas empresas listadas na BM\&FBovespa nos anos de 2011 a 2014?

A divulgação de relatórios ambientais iniciou-se, basicamente, na década de 1990 e o objetivo dessa evidenciação é divulgar informações acerca do desempenho econômico, financeiro, social e ambiental das entidades aos diversos stakeholders (Tinoco e Kraemer, 2011). O número de empresas listadas na BM\&FBovespa que divulga o Relatório de Sustentabilidade aumentou em $70 \%$ no ano de 2014 em comparação com 2012, ano de criação do Relate ou Explique.

A configuração global da maioria das empresas requer que as mesmas evidenciem o grau de preocupação e amadurecimento, demonstrando que há uma consciência ambiental desenvolvida, tornando público o atendimento de requisitos ambientais (Paiva, 2003). Sendo assim, a proposta do trabalho se justifica pela necessidade de entender quais fatores contribuem para as empresas divulgarem informações socioambientais, uma vez que não há, para a maioria delas, a obrigatoriedade de tal prática.

Logo, o objetivo desse estudo é identificar quais variáveis são capazes de influenciar na probabilidade de publicação do Relatório de Sustentabilidade ou Relato Integrado pelas empresas listadas na BM\&FBovespa nos anos de 2011 a 2014. As variáveis a serem testadas são o tamanho da empresa, sua rentabilidade, o nível de governança corporativa, a participação na carteira do Índice de Sustentabilidade Empresarial (ISE) e o setor da mesma.

Esse artigo segue com mais cinco sessões que abordam a revisão de literatura, as hipóteses de pesquisa, a metodologia utilizada, os resultados e conclusões da análise.

Revista de Gestão Social e Ambiental - RGSA, São Paulo, v. 11, n. 1, p. 90-104, jan./abr. 2017. 


\section{REVISÃO DE LITERATURA}

Desenvolvimento econômico e meio ambiente saudável são elementos indissociáveis e é urgente conciliá-los, visto que são vitais para a sobrevivência da humanidade (Ribeiro, 2010). As empresas, com o passar dos anos e a partir das demandas sociais, começaram a desenvolver essa racionalidade ambiental e, assim, o desenvolvimento sustentável, quando voltado para o ambiente corporativo, está diretamente relacionado ao conceito de responsabilidade social corporativa. Essa concepção remete ao comportamento empresarial capaz de integrar elementos sociais e ambientais, que vão além das exigências legais e atendem às expectativas da sociedade em relação à empresa (Araya, 2003; Dias, 2011). Nesse contexto, a Organization for Economic Co-operation and Development - Oecd (2001, p. 9), afirma que "[...]as iniciativas voluntárias na área de responsabilidade corporativa estão entre as principais tendências em negócios internacionais nos últimos anos". A organização afirma ainda que a maioria das empresas multinacionais adere a essa iniciativa e que essa atitude envolve compromisso nas áreas trabalhista, ambiental, direitos humanos, proteção ao consumidor, divulgação e combate à corrupção. Dessa maneira, de acordo com Dias (2011), a empresa passa a desenvolver funções que vão além do mercado, cumprindo, assim, além de seu papel econômico, seu papel social.

Existem diversas formas de uma organização desenvolver seu papel social, uma delas é com a divulgação de informações sobre os impactos ambientais e sociais. Essa divulgação está diretamente relacionada com a busca por legitimidade da organização, visto que a mesma precisa ser aceita e legítima perante a sociedade (Neu, Warsame \& Pedwell, 1998; Braga \& Salotti, 2008; Carneiro, Silva, Santos \& Santos, 2012). Assim, o estudo desses autores mostra que as companhias tentam evidenciar as informações gerais e socioambientais ao público mais relevante a fim de alcançar a aceitação social.

O disclosure, de cunho social e ambiental, iniciou-se lentamente em alguns países por volta de 1900. Entretanto, somente a partir de meados da década de 1990 que tal ação se tornou mais popular, mas essas informações ainda integravam os relatórios anuais tradicionais das companhias. Com o advento da internet e a influência de tal popularização, no fim dos anos 1990 algumas empresas começaram a publicar os relatos socioambientais de forma separada das demonstrações tradicionais. Como na maioria dos países essa divulgação não é compulsória, não há um padrão obrigatório a ser seguido. No entanto, entidades como Global Reporting Initiative (GRI) já propuseram um guia de orientação às empresas para relatarem seus aspectos sociais e ambientais (Deegan \& Unerman, 2011).

O modelo proposto pelo GRI é chamado de Global Reporting Initiative's Sustainability Reporting Guidelines (GRI Guidelines) e visa oferecer a definição dos princípios e conteúdos a serem abordados e um manual de implementação para elaboração de relatório de sustentabilidade, abrangendo as categorias econômica, ambiental e social. Esses relatórios visam à divulgação de informações sobre os impactos de uma organização sobre a sociedade, a economia e o meio ambiente, sejam esses positivos ou negativos (GRI, 2013).

Mais recentemente surgiu o Relato Integrado, proposto pelo International Integrated Reporting Council (Iirc), que tem o objetivo de apresentar aos principais financiadores como a entidade gera valor em longo prazo. A estrutura desenvolvida pelo Iirc apresenta os princípios básicos para elaboração do relato e os elementos de conteúdo, indicando que devem ser incluídas informações quantitativas e qualitativas, normalmente organizadas em capitais, a saber, financeiro, manufaturado, intelectual, humano, social, de relacionamento e natural (Iirc, 2014).

Para fins desse trabalho, observou-se se as companhias publicaram o relatório de sustentabilidade ou relato integrado. Como a pesquisa não abrangeu a qualidade da publicação, não foi observado se os relatórios feitos com base em uma das duas diretrizes citadas cumpriam todos os requisitos propostos.

Observando os estudos sobre divulgações sociais e ambientais, encontra-se a pesquisa de Gallego-Álvarez e Quina-Custodio (2016) que analisou a divulgação voluntária sobre 
responsabilidade social corporativa em 110 empresas incluídas no site da GRI no ano de 2014 de diferentes setores e países, tais como França, Portugal, Espanha, Reino Unido e EUA. Para essa análise, os autores utilizaram um modelo de regressão múltipla a fim de verificar quais variáveis afetam a divulgação de informações econômicas, sociais e ambientais. Os resultados indicam que o tamanho e a inovação influenciam a divulgação sob as três esferas citadas, sendo que o tamanho tem relação positiva e a inovação negativa. Já a alavancagem da empresa influencia apenas no âmbito econômico, enquanto a estrutura jurídica do país afeta a divulgação de informações ambientais, ambos de forma positiva. Já a rentabilidade não apresentou relação significativa com a divulgação de informações sobre RSC.

De forma similar, Habbash, Hussainey e Awad (2016) tiveram por objetivo identificar o nível de disclosure voluntário da Arábia Saudita e quais fatores influenciam nessa divulgação. Ao analisar 361 empresas entre os anos de 2007 e 2011, os autores encontraram que a média de disclosure voluntário era de 18,38\%, sendo que as variáveis tamanho, idade, rentabilidade, especialização do auditor, propriedade familiar e tipo de setor afetam positivamente essa divulgação. Por outro lado, a alavancagem possui relação negativa com o disclosure. Já as variáveis "independência do conselho", "empresa auditada por Big4" e "propriedade estatal" não apresentaram relações significativas para a amostra estudada.

Em âmbito nacional, Batista, Cruz e Bruni (2016) estudaram as variáveis que influenciaram o nível de divulgação ambiental em 2014 das 52 maiores organizações transnacionais, segundo a Fundação Dom Cabral. Os resultados da regressão linear múltipla utilizada apontam, por um lado, que há uma relação positiva entre o grau de internacionalização da empresa e o nível de divulgação ambiental. Por outro, as variáveis tamanho, desempenho, reputação corporativa e endividamento não apresentaram relações significativas nessa pesquisa.

Em pesquisa semelhante, Rover, Tomazzia, Murcia e Borba (2012) buscaram identificar os fatores que determinam a divulgação voluntária ambiental pelas empresas brasileiras listadas na BM\&FBovespa e potencialmente poluidoras no período de 2005 a 2007. Constatou-se que as variáveis tamanho, empresas auditadas por big four, sustentabilidade e divulgação do Relatório de Sustentabilidade estão correlacionados com o nível de disclosure ambiental.

Englobando alguns países da América Latina, o estudo de Calixto (2013) analisou as informações socioambientais de 226 companhias da Argentina, Brasil, Chile, México e Peru nos relatórios publicados no período de 2004 a 2009. As informações foram segregadas por país, empresa, setor e ano utilizando as diretrizes voluntárias do GRI. Os resultados da pesquisa revelaram que a maioria das companhias de capital aberto não disponibiliza informações socioambientais nos seus relatórios anuais ou em relatórios específicos sobre o tema, entretanto as companhias estabelecidas no Brasil são as que mais se destacam no assunto. Quanto à evolução e à forma de divulgação de informações socioambientais, verificou-se que o relatório anual é o principal canal utilizado pelas companhias para destacar tais informações, seguido do relatório de sustentabilidade, divulgado como parte do relatório anual ou como uma publicação específica.

Usando o método de análise de conteúdo, Nossa (2002) analisou os relatórios ambientais das 42 maiores empresas das 50 existentes do setor de papel e celulose em nível internacional, além de 8 empresas das 10 maiores do Brasil nesse setor. Ele constatou que o disclosure de informações ambientais apresentado pelas empresas do setor diverge entre as companhias com relação ao tamanho da empresa (quanto maior o tamanho da empresa, mais detalhada é a apresentação do disclosure das informações ambientais), ao país de localização e ao tipo de relatório (financeiro ou específico), sendo a maioria das informações ambientais predominantemente descritivas e evidenciadas em relatórios ambientais específicos. Além disso, o nível de divulgação ambiental de empresas brasileiras de papel e celulose é menos detalhado que a média de outros países nesse mesmo setor.

Com o objetivo de identificar quais fatores afetam na divulgação do relato integrado, FriasAceituno, Rodríguez-Ariza e Garcia-Sánchez (2012) estudaram as duas mil maiores companhias internacionais de acordo com a lista Forbes Global 2000, nos anos de 2008 a 2010, com base nas 
teorias da agência, sinalização, do custo político e do custo de propriedade. Eles concluíram que empresas que atuam em setores de maior concentração têm menor probabilidade de publicar informações relevantes nos relatos integrados, já o tamanho e a rentabilidade da empresa afetam positivamente tal disclosure, enquanto a oportunidade de crescimento da entidade não teve resultados significativos.

Ainda sobre o relato integrado, Marques (2016) investigou quais as características da empresa e do país incentivaram a publicação desse relatório em 2014 por 656 empresas localizadas em diferentes países: Alemanha, Bélgica, Dinamarca, Espanha, Finlândia, França, Grécia, Irlanda, Itália, Holanda, Portugal e Reino Unido. Por meio de uma regressão logística, observou-se que as características tamanho, estrutura acionista, rentabilidade, forma de financiamento e classificação setorial das empresas não foram significativas. Já os atributos do país de origem da empresa, que são a representação coletiva dos interesses dos trabalhadores por meio de sindicatos e a importância da participação cívica na criação legislativa e na atuação governamental, influenciaram positivamente a publicação do Relato Integrado.

\section{HIPÓTESES DE PESQUISA}

Existem diversas abordagens teóricas para explicar o fenômeno da divulgação, como por exemplo, a teoria dos stakeholders, teoria da legitimidade, teoria da agência e teoria da divulgação. Nenhuma delas é abrangente ou unificada e, portanto, não há um paradigma central que dá origem a todas as pesquisas subsequentes (Verrecchia, 2001). Sendo assim, a abordagem utilizada predominantemente neste trabalho é a teoria da divulgação. Essa teoria, segundo Verrecchia (2001), caminha na direção de uma teoria mais abrangente e o autor sugere três grandes categorias de divulgação que baseiam a pesquisa sobre essa temática: (1) associação (exógeno): associação entre a divulgação e a mudança no comportamento dos investidores; (2) julgamento (endógeno): divulgação baseada em discricionariedade, procurando entender como os gestores divulgam as informações e quais são os motivos para divulgar; (3) eficiência: quais arranjos de divulgação são preferidos na ausência de conhecimento prévio sobre a informação.

A pesquisa sobre divulgação baseada em julgamento é a abordagem compatível com este trabalho, já que esse visa identificar quais fatores influenciam na probabilidade de divulgação do Relatório de Sustentabilidade pelas empresas listadas na BM\&FBovespa entre os anos de 2011 a 2014. Dentro dessa abordagem, Salotti e Yamamoto (2005) destacam que se o processo de disclosure de uma entidade começa a ser tratado como um processo interno (endógeno), os estudos passam a indagar quais as causas da escolha da administração em divulgar ou não certas informações, dessa maneira é possível inferir e testar quais fatores influenciarão para dadas evidenciações.

Diante do exposto, se torna possível elencar algumas hipóteses sobre as influências na divulgação de relatório de sustentabilidade ou relato integrado pelas empresas listadas pela BM\&FBovespa. Assim, de acordo com a literatura, foram identificados cinco potenciais fatores que influenciam na divulgação ambiental das empresas: tamanho, rentabilidade, governança corporativa, ISE e setor. As hipóteses referentes a esses fatores são apresentadas nos tópicos seguintes.

\subsection{Tamanho}

As empresas maiores, segundo Frias-Aceituno et al. (2012), utilizam de forma mais ampla os mercados de capitais para obterem financiamento do que empresas de porte menor. Isso implica diretamente na quantidade e qualidade da informação divulgada, já que elas sinalizam a situação da empresa para o mercado. De acordo com a teoria da agência, essas informações têm o potencial de diminuir os custos advindos dos conflitos dessa relação, principalmente quando o disclosure é de 
cunho voluntário (Frias-Aceituno et al., 2012), como os relatórios de sustentabilidade ou relato integrado para alguns setores brasileiros.

Algumas pesquisas, tais como as de Ahmed e Courtis (1999), Leventis e Weetman (2004), Alsaeed (2006), Watson, Shrives e Marston (2002), Gallego-Álvarez e Quina-Custodio (2016), Habbash, Hussainey e Awad (2016), já concluíram sobre a relação positiva entre o tamanho da empresa e sua aptidão para divulgação de informações de cunho financeiro e/ou socioambiental. Diante disso, sugere-se a seguinte hipótese:

H1: Empresas maiores possuem maior probabilidade de divulgação ambiental que empresas menores.

\subsection{Rentabilidade}

A seleção adversa, para Akerlof (1970), surge sempre que existe liberdade de escolha. Como há um trade-off entre os custos e benefícios de informar ao mercado o valor da empresa, as companhias altamente rentáveis se beneficiam mais ao informar sobre seu desempenho positivo, evitando, assim, a assimetria informacional decorrente da seleção adversa (Troberg, Kinnunen e Seppänen, 2010).

Dessa forma, espera-se que empresas mais rentáveis tenham maior probabilidade de divulgar informações a fim de diferenciar-se das demais, por conseguinte, elas terão maior probabilidade de publicar o relatório de sustentabilidade ou relato integrado, sugerindo a segunda hipótese:

H2: Empresas mais rentáveis possuem maior probabilidade de divulgação ambiental que empresas menos rentáveis.

\subsection{Governança corporativa}

Governança corporativa é um conjunto de mecanismos por meio dos quais os investidores externos se protegem contra a expropriação dos gestores ou controladores (La Porta, Silanes, Shleifer e Vishny, 2000). Os níveis de governança corporativa criados pela BM\&FBovespa para melhorar a avaliação das companhias, asseguram a divulgação de informações mais completas, atraindo, assim, mais investidores. Alguns estudos, tal como o de Murcia e Santos (2009), já confirmaram uma relação positiva entre o nível de disclosure voluntário de caráter econômico e as empresas que aderem aos níveis diferenciados de governança corporativa.

Considerando que são maiores as exigências relacionadas às informações para as empresas que aderem aos níveis de Governança da BM\&FBovespa, sugere-se a terceira hipótese:

H3: Empresas que aderem aos níveis diferenciados de governança corporativa da BM\&FBovespa (Nível 2 e Novo Mercado) possuem maior probabilidade de divulgação ambiental do que aquelas que não aderem a tais níveis.

\subsection{ISE}

O Índice de Sustentabilidade Empresarial (ISE), criado pela BM\&FBovespa, se originou objetivando um contexto compatível com as necessidades de desenvolvimento sustentável da atualidade e para motivar a sustentabilidade empresarial pautada pela eficiência econômica, equilíbrio ambiental e justiça social. $\mathrm{O}$ índice, atualmente, é composto por 40 empresas entre as listadas na BM\&FBovespa que possuem as 150 ações mais líquidas no mercado. Essas entidades são selecionadas ao cumprirem alguns requisitos e responderem um questionário com questões gerais e de cunho ambiental e social. Normalmente, organizações que fazem parte da carteira do ISE são de grande porte e estão inseridas em mercados com grande foco de ambientalistas (Nunes, Teixeira, Nossa e Galdi, 2010). Devido a isso, espera-se que haja uma relação positiva entre uma 
companhia integrante da carteira do ISE e sua probabilidade de divulgação de relatório de sustentabilidade ou relato integrado, assim sugere-se a quarta hipótese:

H4: Empresas que compõem a carteira do ISE da BM\&FBovespa possuem maior probabilidade de divulgação ambiental do que empresas não compõem a carteira.

\subsection{Setor}

O setor de atividade das empresas impacta diretamente em seus relatórios sociais e ambientais. Nossa (2002), baseado nos estudos da KPMG (1999) e Cormier e Magnan (1997), concluiu que os relatórios têm grande variação entre as companhias de diferentes setores e que as que possuem maior grau de impacto ambiental tendem a produzir mais relatórios, visto que pelas características de sua atividade, elas possuem deveres ambientais subjacentes.

Nesse estudo, definiu-se que os setores de maior impacto ambiental, de acordo com a classificação proposta pelo Com dinheiro, são: (a) biocombustíveis, gás e petróleo, (b) celulose, papel e madeira, (c) metalurgia e siderurgia, (d) mineração e (e) petroquímico. A partir do exposto, definiu-se a quinta hipótese:

H5: Empresas que se inserem em setores com atividades de alto grau de impacto ambiental possuem maior probabilidade de divulgação ambiental do que empresas que se inserem em outros setores.

\section{METODOLOGIA}

A pesquisa pode ser caracterizada como teórica e empírica, visto que se buscou identificar quais fatores influenciam na divulgação do relatório de sustentabilidade ou relato integrado pelas empresas brasileiras, baseando as hipóteses em construtos teóricos já fundamentados. Além disso, ela tem uma abordagem predominantemente quantitativa, pois usa de argumentações já definidas para desenvolver novos conhecimentos a partir do uso de coleta de dados e análise estatística (Creswell, 2007).

Esse estudo engloba as empresas brasileiras listadas na BM\&FBovespa que estavam presentes na lista divulgada pela bolsa denominada "Relate ou Explique". Os dados secundários das companhias, utilizados para a estimação econométrica, foram obtidos por meio da base de dados Comdinheiro.

O período de análise abrange os anos de 2011 a 2014, dessa forma, a amostra contou com 1.544 observações, tendo sido eliminadas as companhias que não apresentaram todas as informações necessárias em, pelo menos, um dos quatro anos de análise. Assim, foram analisadas 386 empresas por ano, o que representa mais de $90 \%$ das empresas listadas nos anos citados.

Como esse estudo tem o objetivo de verificar quais fatores influenciam na probabilidade de divulgação do relatório de sustentabilidade ou relato integrado, optou-se por um modelo logit com dados empilhados e erros-padrão robustos clusterizados e um modelo logit em painel com efeitos aleatórios.

A BM\&FBovespa, a partir de 2011, exige que as empresas divulguem se publicam tais relatórios e onde eles se encontram ou os motivos de não o fazerem. A partir dessa listagem, obtida no site da bolsa de valores brasileira, foi criada a variável dependente dicotômica "divulgação" (DIV), que assume valor 1 para publicação de um dos relatórios e 0 em caso contrário. Por isso, o modelo logit foi escolhido, visto que, segundo Gujarati e Porter (2011), quando há uma variável dependente de escolha binária, o objetivo do modelo é apontar a probabilidade de que aquele evento aconteça, dado as variáveis independentes. Assim, alguns modelos podem ser utilizados, sendo um dos mais indicados o logit.

Para testar as hipóteses por meio dos modelos propostos, utilizaram-se as seguintes proxies como variáveis independentes:

- Tamanho (TAM): logaritmo natural do ativo total de cada empresa;

Revista de Gestão Social e Ambiental - RGSA, São Paulo, v. 11, n. 1, p. 90-104, jan./abr. 2017. 
- Rentabilidade (REN): rentabilidade sobre o patrimônio líquido, calculada a partir do quociente entre o lucro líquido e o total do patrimônio líquido de cada companhia;

- Governança corporativa (GC): variável dicotômica de valor 1 para empresas pertencentes aos níveis de Governança Corporativa da BM\&FBovespa (Novo Mercado e Nível 2) e 0 para as demais;

- Carteira do ISE (ISE): variável dicotômica de valor 1 para empresas que compõem a carteira do ISE da BM\&FBovespa e 0 para as demais;

- Setor (SET): variável dicotômica de valor 1 para empresas que se inserem em setores com atividades de alto grau de impacto ambiental e 0 para as demais.

Com essas variáveis, é possível estimar o modelo pooled logit com erros-padrão robustos clusterizados, que é um modelo cross-section. Os erros-padrão robustos clusterizados foram usados para, segundo Cameron e Trivedi (2009), corrigir possíveis correlações de erros de alguns indivíduos ao longo do tempo.

Já o painel logit com efeitos aleatórios, segundo Wooldridge (2010), é aquele que trata as variáveis não abrangidas pelo modelo como aleatórias. Dessa forma, o mesmo define o efeito individual específico como uma variável aleatória não observada com a distribuição especificada (Cameron \& Trivedi, 2009).

O painel logit com efeitos fixos, por outro lado, segundo Wooldridge (2010), trata as variáveis não especificadas como um parâmetro que é estimado por cada uma das observações cross-section. Entretanto, ele não foi utilizado nesse estudo, pois, segundo Greene (2012), o problema mais latente do modelo de efeitos fixos é que o estimador não consegue acomodar variáveis que não se alteram com o tempo. Como o setor e a governança corporativa das companhias não variaram ao longo dos quatro anos analisados, esse modelo não se mostrou relevante.

Com os modelos propostos, pode-se então avaliar a significância dos coeficientes das variáveis independentes e o sinal dos mesmos e, assim, validar ou não as hipóteses elaboradas.

\section{RESULTADOS E DISCUSSÕES}

Inicialmente, ao analisar as estatísticas descritivas das variáveis, nota-se que $35,68 \%$ das companhias analisadas publicaram o relatório de sustentabilidade ou relato integrado nos quatro anos. Comparando esse percentual entre os anos, observa-se, que em 2011, apenas $23 \%$ das empresas publicavam um dos relatórios, no entanto, a partir de 2012, esse montante se elevou e permaneceu próximo de $40 \%$ nos anos que se seguiram.

Quanto ao tamanho das empresas, como pode ser verificado na Tabela 1, há um valor médio de 20,96, levando em conta o logaritmo natural do total de seus ativos, sendo que essa medida é maior para as empresas que fazem tal divulgação do que para as que não fazem, 22,6 e 20,04, respectivamente. Quanto à rentabilidade, a média geral é de 70,97 e, nesse caso, nota-se o contrário, ou seja, a maior média é das empresas que não divulgam, 106,20. Enquanto isso, 36,01\% das empresas analisadas possuem um dos níveis diferenciados de governança corporativa da BM\&FBovespa, sendo que entre as que não divulgam esse percentual é menor $(30,21 \%)$ se comparado com o das empresas que divulgam (46,46\%). Observa-se que 10,36\% das empresas totais pertencem aos setores considerados mais agressivos ao meio ambiente, enquanto, entre as empresas que divulgam, esse percentual é de $11,79 \%$ e para as demais 9,56\%. Das companhias analisadas, 9,84\% fazem parte da carteira do ISE, sendo que a maior parte delas é de empresas que divulgam. 
Tabela 1: Estatísticas descritivas

\begin{tabular}{cccccc}
\hline \multicolumn{7}{c}{ Empresas que não divulgam } & & Mesvio- \\
Variável & $\begin{array}{c}\text { N. de } \\
\text { observações }\end{array}$ & Média & $\begin{array}{c}\text { Desvíno } \\
\text { padráo }\end{array}$ & Máximo \\
\hline TAM & 993 & 20.04759 & 2.865433 & 7.6 & 25.78 \\
\hline REN & 993 & 106.2054 & 2559.101 & -6357.42 & 60012.72 \\
\hline Variável & $\begin{array}{c}\text { N. de } \\
\text { observações }\end{array}$ & Média & $\begin{array}{c}\text { Desvio- } \\
\text { padrão }\end{array}$ & Mínimo & Máximo \\
\hline TAM & 551 & 22.61207 & 1.727958 & 17.73 & 27.88 \\
\hline REN & 551 & 7.480491 & 268.0983 & -5451.53 & 2835.61 \\
\hline Variável & $\begin{array}{c}\text { N. de } \\
\text { observações }\end{array}$ & Média & $\begin{array}{c}\text { Desvio- } \\
\text { padrão }\end{array}$ & Mínimo & Máximo \\
\hline TAM & 1544 & 20.96277 & 2.802386 & 7.6 & 27.88 \\
\hline REN & 1544 & 70.97389 & 2058.696 & -6357.42 & 60012.72 \\
\hline
\end{tabular}

Fonte: Elaborada pelos autores

O logit foi estimado com o modelo pooled com erros-padrão robustos clusterizados e com o painel de efeitos aleatórios. Na primeira estimação, somente as variáveis tamanho e participação no ISE foram significativas a $1 \%$ e tiveram os sinais esperados. O modelo como um todo também foi significativo a $1 \%$, visto que prob $>$ chi $2=0.0000$, como mostra a Tabela 2 . Ao inserir dummies no modelo para representar os anos de estudo, observou-se significância nas mesmas variáveis ao nível de $1 \%$, o que demonstra que a variação temporal influencia na probabilidade de publicação dos relatórios.

Tabela 2: Estimação do pooled logit com erros-padrão robustos clusterizados

\begin{tabular}{ccccc}
\hline Variáveis & $\begin{array}{c}\text { Razão de } \\
\text { Chances }\end{array}$ & $\begin{array}{c}\text { Erro-padrão } \\
\text { robusto }\end{array}$ & Estatística $\mathbf{z}$ & p-valor \\
\hline TAM & 1.654721 & 0.1105662 & $7.54^{* * *}$ & \\
\hline REN & 0.9999837 & 0.0000423 & -0.39 & 0.000 \\
\hline GC & 1.055813 & 0.2339243 & 0.25 & 0.700 \\
\hline ISE & 15.02849 & 6.65227 & $6.12^{* * *}$ & 0.000 \\
\hline SET & 0.8442715 & 0.2842292 & -0.50 & 0.615 \\
\hline CONS & $9.27 \mathrm{e}-06$ & 0.0000131 & $-8.21^{* * *}$ & \\
\hline Wald chi2 $=116.85$ & & & \\
Prob> chi2 $=0.0000$ & & & \\
\hline
\end{tabular}

*** Indica significância dos coeficientes a um nível de significância de $1 \%$.

Fonte: Elaborada pelos autores

Quanto à significância das variáveis, os mesmos resultados foram encontrados com o painel logit estimado com efeitos aleatórios, como mostra a Tabela 3. Tal painel é balanceado, visto que cada empresa (unidade cross-section) possui a mesma quantidade de observações temporais. Entretanto, o coeficiente da razão de chances foi diferente entre os modelos. Esse modelo também foi significativo como um todo a um nível de significância de $1 \%$. 
Tabela 3: Estimação do painel logit com efeitos aleatórios

\begin{tabular}{ccccc}
\hline Variáveis & $\begin{array}{c}\text { Razão de } \\
\text { Chances }\end{array}$ & Erro-padrão & Estatística $\mathbf{z}$ & p-valor \\
\hline TAM & 4.081541 & 0.77153 & $7.44^{* * * *}$ & 0.000 \\
\hline REN & 0.9998424 & 0.00036 & -0.44 & 0.662 \\
\hline GC & 1.286401 & 0.6336088 & 0.51 & 0.609 \\
\hline ISE & 114.9604 & 116.2616 & $4.69^{* * *}$ & 0.000 \\
\hline SET & 0.7581148 & 0.5998156 & -0.35 & 0.726 \\
\hline CONS & $8.96 \mathrm{e}-15$ & $3.70 \mathrm{e}-14$ & $-7.83^{* * *}$ & 0.000 \\
\hline
\end{tabular}

Wald chi $^{2}=84.17$

Prob $>$ chi $2=0.0000$

*** Indica significância dos coeficientes a um nível de significância de $1 \%$.

Fonte: Elaborada pelos autores

Portanto, a significância da variável "tamanho" mostra que quanto maior for a empresa, maiores serão suas chances de publicar relatório de sustentabilidade ou relato integrado. Da mesma forma, empresas integrantes da carteira do ISE também possuem maiores chances de fazerem tal publicação.

Por outro lado, as variáveis "rentabilidade", "nível de governança corporativa" e "setor com alto impacto ambiental" não tiveram resultados significativos nas chances de uma companhia publicar relatório de sustentabilidade ou relato integrado.

A partir dos resultados obtidos na análise econométrica, pode-se inferir sobre os fatores que influenciam na probabilidade das empresas listadas na BM\&FBovespa divulgarem o relatório de sustentabilidade ou relato integrado. Os resultados obtidos e a confirmação ou não das hipóteses, pode ser visualizada na Tabela 4 .

Tabela 4: Conclusão sobre as hipóteses

\begin{tabular}{cccc}
\hline Variável & $\begin{array}{c}\text { Sinal esperado do } \\
\text { coeficiente }\end{array}$ & $\begin{array}{c}\text { Resultado do } \\
\text { coeficiente }\end{array}$ & Conclusão sobre a hipótese \\
\hline TAM & + & + & Confirmada \\
\hline REN & + & Não significante & Não confirmada \\
\hline GC & + & Não significante & Não confirmada \\
\hline ISE & + & + & Confirmada \\
\hline SET & + & Não significante & Não confirmada \\
\hline
\end{tabular}

Fonte: Elaborada pelos autores

Como mostrado, as hipóteses confirmadas foram "H1: Tamanho" e "H4: ISE". Resultado semelhante foi encontrado no estudo de Coelho, Pires e Alves (2010), que confirmou que apenas as variáveis tamanho e sustentabilidade (ISE) possuem significância estatística para explicar o nível de divulgação de informações voluntárias. Da mesma forma, Rover e Santos (2014) confirmaram que essas variáveis foram positivamente significativas com a divulgação voluntária de informações socioambientais nas 91 empresas do Índice Brasil de 2011, ao analisarem as demonstrações publicadas entres 2008 e 2010.

Quanto à confirmação da primeira hipótese, isso implica que o tamanho da empresa afeta positivamente suas chances de evidenciar informações via relatório de sustentabilidade ou relato integrado. Esse resultado foi encontrado também nos estudos de Murcia e Santos (2009), GallegoÁlvarez e Quina-Custodio (2016) e Habbash et al. (2016), que concluíram que o tamanho está diretamente relacionado nível de disclosure voluntário. Pereira e Lucena (2015) também chegaram à mesma conclusão ao estudarem os fatores de divulgação voluntária do relatório de sustentabilidade dos setores de energia elétrica e telecomunicações nos anos de 2010 a 2014.

As pesquisas de Kneipp, Vieira, Bender Filho e Gomes (2013) constataram também que a variável tamanho afetou os índices de divulgação de sustentabilidade de 97 empresas no ano de 
2010. Rufino e Monte (2014) também atestaram que o tamanho da empresa influenciou na divulgação voluntária das 100 empresas não-financeiras com ações mais negociadas em 2012.

Já a participação no ISE indica que quando uma companhia está listada na carteira do ISE ela tem maiores chances de publicar um dos relatórios citados. Esse resultado vai ao encontro dos estudos de Santos, Gomes e Almeida (2015) que também concluíram que empresas pertencentes à carteira do ISE foram as que mais divulgaram informações ambientais no ano de 2013, sendo analisados 39 relatórios ambientais. Também corroboram com os resultados de Murcia, Fávero, Rover, Lima e Lima (2008) que apontaram para a relevância da participação no ISE nas razões do disclosure voluntário ambiental ao analisarem as empresas classificadas como de setores de alto impacto ambiental, listadas na bolsa de valores brasileira em 2006.

Por outro lado, as hipóteses "H2: Rentabilidade", "H3: Nível de Governança Corporativa" e "H5: Setor de alto impacto" não apresentaram resultados conclusivos nessa pesquisa. Assim não se pode afirmar que esses fatores influenciam a probabilidade de uma companhia divulgar ou não tais relatórios. Outros pesquisadores encontraram resultados semelhantes, tais como Gallego-Álvarez e Quina-Custodio (2016), que não observaram relação significativa entre a rentabilidade e a divulgação de informações sobre RSC ao analisar as 110 empresas citadas no site do GRI em 2014; Hackston e Milne (1996) que, ao examinarem as 50 maiores companhias da Nova Zelândia, não encontraram significância na relação entre rentabilidade e divulgação de informações socioambientais; Oliveira e Salotti (2009) que também não perceberam significância entre desempenho e governança corporativa com o nível de divulgação ambiental de 108 empresas brasileiras não financeiras em 2006; Alsaeed (2006) que obteve resultados de que as variáveis relacionadas à rentabilidade (margem de lucro e retorno sobre o patrimônio) e o tipo de indústria também não possuem relação significativa com divulgação voluntária de 40 firmas não financeiras da Arábia Saudita em 2003; Batista et al. (2016) que não encontraram relação significativa entre a rentabilidade e a reputação corporativa como o nível de divulgação ambiental ao estudarem as 52 maiores organizações transnacionais brasileiras em 2014; Marques (2016) que observou que a rentabilidade e o setor não afetaram, de forma significativa, a probabilidade das 656 empresas estudadas publicarem o Relato Integrado em 2014; Burgwal e Vieira (2014), por sua vez, ao estudarem 28 companhias holandesas no ano de 2008, também não encontraram relação significativa entre a rentabilidade e o nível de divulgação socioambiental das empresas, no entanto, os resultados se contrapõem aos apresentados nesse estudo quanto a variável setor de alto impacto ambiental, visto que eles encontraram relação positiva e significativa entre essa variável e a divulgação ambiental.

Os resultados desse artigo também divergem dos achados de Murcia e Santos (2009), que encontraram relação positiva entre à aderência aos níveis de governança corporativa da BM\&FBovespa e o nível de disclosure voluntário econômico. Kneipp et al. (2013) também chegaram a resultados divergentes, pois encontraram relação positiva entre setores de maior impacto ambiental e maior índice de divulgação de sustentabilidade. Assim como Rufino e Monte (2014) e Habbash et al. (2016), concluíram que a rentabilidade é um fator determinante da divulgação voluntária de informações ambientais.

Este trabalho diferencia-se dos demais por considerar apenas se a empresa divulga ou não o Relatório de Sustentabilidade ou Relato Integrado, não levando em conta o nível de disclosure. Sendo assim, as comparações realizadas se limitam aos fatores que levam as empresas a fazerem tal divulgação, não entrando no mérito da quantidade ou qualidade da informação divulgada.

\section{CONSIDERAÇÕES FINAIS}

Tendo como objetivo verificar quais fatores influenciam na probabilidade de divulgação do relatório de sustentabilidade ou relato integrado, esse estudo utilizou modelos logit com dados empilhados e erros-padrão robustos clusterizados e logit em painel com efeitos aleatórios para testar as hipóteses de que as variáveis "tamanho", "rentabilidade", "nível de governança corporativa", 
"participação no ISE" e "setor de alto impacto" possuem influência positiva em tal disclosure. As hipóteses foram baseadas na teoria da divulgação e em estudos anteriores.

Assim, encontrou-se, a partir de 386 empresas listadas na BM\&FBovespa nos anos de 2011 a 2014, que as variáveis "tamanho" e "participação no ISE" influenciaram positivamente a probabilidade de uma empresa publicar um dos relatórios. De forma contrária, as variáveis "rentabilidade", "nível de governança corporativa" e "setor de alto impacto" não tiveram resultados significativos nos modelos, dessa forma não se pode inferir se há influência das mesmas.

Diante disso, conclui-se que a probabilidade de uma companhia publicar o relatório de sustentabilidade ou relato integrado é expandida quanto maior for o tamanho da empresa ou quando a mesma fizer parte da carteira do ISE. Entretanto, pela não confirmação das outras três hipóteses, não se pode concluir que haja influência da rentabilidade, do nível de governança corporativa e do setor da empresa em suas chances de divulgação.

Como limitações da pesquisa, encontram-se a utilização de poucas variáveis para teste e não consideração da qualidade do relatório de sustentabilidade ou relato integrado publicado pelas empresas nesses anos. Dessa maneira, sugerem-se novos estudos abordando o impacto dessas e de outras variáveis na qualidade dos relatórios publicados não só pelas empresas brasileiras, mas também a nível internacional.

\section{REFERÊNCIAS}

Ahmed, K., Courtis, J. K. (1999) Associations between corporate characteristics and disclosure levels in annual reports: a meta-analysis. British Accounting Review, 31, 35-61.

Akerlof, G. (1970) The market for "lemons": quality, uncertainty and market mechanism. Quarterly Journal of Economic, 84(3), 488-500.

Alencar, J. L. S. de., Simoni, J. H., Fiorelli, M. N., Angelis-Neto, G. de. (2015) Sistema de gestão ambiental e ISO 14000 na indústria têxtil - A sustentabilidade como tendência. Revista Eletrônica em Gestão, Educação e Tecnologia Ambiental Santa Maria, 19(2), 575-586.

Alsaeed, K. (2006) The association between firm-specific characteristics and disclosure: The case of Saudi Arabia. Managerial Auditing Journal, 21(5), 476-496.

Araya, M. (2003) Negociaciones de inversión y responsabilidad social corporativa: explorando un vínculo en las Américas. Revista ambiente y desarrollo, 19(3/4), 74-81.

Batista, A. B., Cruz, N. V. S., Bruni, A. L. (2016) Fatores determinantes do nível de divulgação ambiental nas maiores transnacionais brasileiras em 2014 segundo a Fundação Dom Cabral. Contextus Revista Contemporânea de Economia e Gestão, 14(3), 140-161.

BM\&FBovespa. (2011) Proposta de adoção ao modelo "Relate ou Explique” para Relatórios de Sustentabilidade ou similares para Empresas listadas. Recuperado em 3 novembro, 2015, de http://www.bmfbovespa.com.br/pt-br/mercados/download/CE-017-2011-Relate-ou-Explique.pdf.

Braga, J. P. \& Salotti, B. M. (2008) Relação entre nível de disclosure ambiental e características corporativas de empresas no Brasil. Anais do Congresso USP de iniciação Científica em Contabilidade, São Paulo, SP, Brasil, 5.

Burgwal, D. van de., Vieira, R. J. O. (2014) Determinantes da divulgação ambiental em companhias abertas holandesas. Revista Contabilidade e Finanças - USP, 25(64), 60-78.

Calixto, L. A. (2013) Divulgação de relatórios de sustentabilidade na América Latina: um estudo comparativo. RA USP - Revista de Administração, 48(4), 828-842. 
Cameron, A.C., Trivedi, P. K. (2009) Microeconometrics using Stata. Stata Press, College Station, Texas.

Carneiro, C. M. B., Silva, P. P., Santos, A. \& Santos, G. P. (2012) A divulgação ambiental no setor de energia elétrica brasileiro. Anais do Congresso Nacional de Excelência em Gestão, Rio de Janeiro, RJ, Brasil, 8.

Coelho, F. Q., Ott, E.; Pires, C. B., Alves, T. W. (2010) Divulgação de informações voluntárias sobre o meio ambiente: uma análise de fatores diferenciadores. Anais do Congresso Brasileiro de Custos, Belo Horizonte, MG, Brasil, 17.

Comissão Mundial sobre Meio Ambiente. (1991). Nosso futuro comum. (2. ed). Rio de Janeiro: Editora da Fundação Getúlio Vargas. Recuperado em 30 novembro, 2015, de http://pt.scribd.com/doc/12906958/Relatorio-Brundtland-Nosso-Futuro-Comum-EmPortugues\#scribd.

Creswell, J. W. (2007) Projeto de pesquisa: métodos qualitativo, quantitativo e misto. (2. ed.). (L. O. Rocha, Trad.). Porto Alegre: Artmed. (Obra original publicada em 2003).

Deegan, C., Unerman, J. (2011) Financial accounting theory. Second European Edition. Berkshire, UK: McGraw-Hill Education.

Dias, R. (2011) Gestão ambiental: responsabilidade social e sustentabilidade. (2. ed.). São Paulo: Atlas.

Frias-Aceituno, J. V., Rodríguez-Ariza, L., Garcia-Sánchez, I. M. (2012) Explanatory factors of integrated sustainability and financial reporting. Business Strategy and the Environment, 23, 56-72.

Gallego-Álvarez, I., Quina-Custodio, I. A. (2016) Disclosure of corporate social responsibility information and explanatory factors. Online Information Review, 40(2), 218-238.

Global Reporting Initiative - GRI (2013) Diretrizes para relato de sustentabilidade. Recuperado em 29 novembro, 2015, de http://www.bmfbovespa.com.br/pt-br/a-bmfbovespa/download/GRI-G4Principios-para-Relato-e-Conteudos-Padrao.pdf

Greene, W. H. (2012) Econometric analysis. (7. ed.). Upper Saddle River: Pearson Education.

Gujarati, D. N.,Porter, C. D. (2011) Econometria Básica. (5. ed.). Porto Alegre: Amgh. (Obra original publicada em 2008).

Habbash, M., Hussainey, K., Awad, A. E. (2016) The determinants of voluntary disclosure in Saudi Arabia: an empirical study. International Journal Accounting, Auditing and Performance Evaluation, 12(3), 213-236.

Hackston, D., Milne, M. J. (1996) Some determinants of social and environmental disclosures in New Zealand companies. Accounting, Auditing \& Accountability Journal, 9(1), 77-108.

International Integrated Reporting Council - Iirc (2014) A estrutura internacional para relato integrado. Recuperado em 29 novembro, 2015, de http://integratedreporting.org/wpcontent/uploads/2015/03/13-12-08-THE-INTERNATIONAL-IR-FRAMEWORK-Portugese-final1.pdf.

Kneipp, J. M., Vieira, K. M.; Bender Filho, R., Gomes, C. M. (2013) Características determinantes no nível de divulgação em relatórios de sustentabilidade de empresas brasileiras. Race - Revista de Administração, Contabilidade e Economia, 12(2), 295-337. 
Kraemer, M. E. P., Behling, G., Rebelo, H. M. \& Goede, W. (2013) Gestão ambiental e sua contribuição para o desenvolvimento sustentável. Anais do Simpósio de excelência e tecnologia. Seropédica, RJ, Brasil, 9.

Leventis, S., Weetman, P. (2004) Voluntary disclosures in an emerging capital market: some evidence from the Athens stock exchange. Advances in International Accounting, 17, 227-250.

Marques, C. S. B. S. (2016) Determinantes do Relato Integrado: uma comparação internacional. Dissertação de Mestrado em Contabilidade e Controlo de Gestão, Universidade do Porto, Porto, Portugal.

Murcia, F. D., Fávero, L. P. L., Rover, S., Lima, G. A. S. F., Lima, I. (2008) 'Disclosure verde’ nas demonstrações contábeis: características da informação ambiental e possíveis explicações para a divulgação voluntária. Revista UnB Contábil, 11(1-2), 260-278.

Murcia, F. D;. Santos, A. (2009) Fatores determinantes do nível de disclosure voluntário das companhias abertas no Brasil. Repec - Revista de Educação e Pesquisa em Contabilidade, 3 (2), 72-95.

Neu, D., Warsame, H., Pedwell, K. (1998) Managing public impressions: environmental disclosures in annual reports. Accounting, Organizations and Society, 23(3), 265-282.

Nossa, V. (2002) Disclosure ambiental: uma análise do conteúdo dos relatórios ambientais de empresas do setor de papel e celulose em nível internacional. Tese de Doutorado em Controladoria e Contabilidade, Universidade de São Paulo, São Paulo, SP, Brasil.

Nunes, J. G., Teixeira, A. J. C., Nossa, V.; \& Galdi, F.C. (2010) Análise das variáveis que influenciam a adesão das empresas ao índice BM\&FBovespa de sustentabilidade empresarial. Base - Revista de Administração e Contabilidade da Unisinos, 7(4), 328-340.

Oliveira, J. R. S.; \& Salotti, B. M. (2009) Determinantes do nível de divulgação ambiental nas demonstrações contábeis de empresas brasileiras, Bahia, Brasil. RC Ufba-Revista de Contabilidade da Ufba, 3(3), 81-95.

Organization for Economic Co-operation and Development (Oecd, 2001) Corporate responsibility: private initiatives and public goals. Paris.

Paiva, P. R. (2003) Contabilidade ambiental: evidenciação dos gastos ambientais com transparência e focada na prevenção. São Paulo: Atlas.

Pereira, M. L.,Lucena, W. G. L. (2015) Determinantes da divulgação voluntária do relatório de sustentabilidade nas empresas de energia elétrica e telecomunicações listadas na BM\&FBovespa. Anais do Congresso Brasileiro de Custos, Foz do Iguaçu, PR, Brasil, 22.

La Porta, R., Silanes, F. L., Shleifer, A. \&Vishny, R. W. (2000) Investor protection and corporate governance. SSRN - Social Science Research Network. Recuperado em 27 dezembro, 2015, de http://papers.ssrn.com/sol3/papers.cfm?abstract_id=183908.

Ribeiro, M. S. (2010) Contabilidade ambiental (5. ed.). São Paulo: Saraiva.

Rover, S., Santos, A. dos. (2014) Revisitando os determinantes do disclosure voluntário socioambiental no Brasil: em busca de robustez na mensuração da variável socioambiental.

Contabilometria - Brazilian Journal of Quantitative Methods Applied to Accounting, 1(2), 15-35. 
Rover, S., Tomazzia, E. C., Murcia, F. D., Borba, J. A. (2012) Explicações para a divulgação voluntária ambiental no Brasil utilizando a análise de regressão em painel. RA USP-Revista de administração, 47(2), 217-230.

Rufino, M. A., Monte, P. A. (2014) Fatores que explicam a divulgação de informações voluntárias das 100 empresas com ações mais negociadas na BM\&FBovespa. Anais do Congresso AnpCont, Rio de Janeiro, RJ, Brasil, 8.

Salotti, B. M.; \& Yamamoto, M. M. (2005) Ensaio sobre a teoria da divulgação. BBR -Brazilian Business Review, 2 (1), 53-70, jan-jun.

Santos, I. L., Gomes, G. S., Almeida, N. S. (2015) Evidenciação ambiental: uma análise das carteiras do ISE, ICO2 e IBovespa. Anais do Congresso USP de Iniciação Científica em Contabilidade, São Paulo, SP, Brasil, 12.

Silva, V. A., De Jesus, M. J. F., Morigi, J. B., \& De Souza, A. D. (2015) Práticas de sustentabilidade na gestão da empresa Cristófoli equipamentos de biossegurança, situada no município de Campo Mourão, Paraná, Brasil. Race - Revista de Administração, Contabilidade e Economia, Unoesc, 14 (2), 479-504.

Tinoco, J. E. P., Kraemer, M. E. P. (2011) Contabilidade e gestão ambiental. (3. ed.). São Paulo: Atlas.

Troberg, P., Kinnunen, J., Seppänen, H. J. (2010) What drives cross-segment diversity in returns and risks? Evidence from Japanese and U.S. firms. The International Journal of Accounting, 45, 4476.

Verrecchia, R. E. (2001) Essays on disclosure. Journal of Accounting \& Economics.32, 97-180, dec.

Watson, A., Shrives, P.,Marston, C. (2002) Voluntary disclosure of accounting ratios in the UK. British Accounting Review, 34, 289-31.

Wooldridge, J. M. (2010) Econometric analysis of cross section and panel data. (2. ed.) Cambridge: MIT Press.

Data da submissão: 05/10/2016

Data de aceite: $15 / 03 / 2017$

Revista de Gestão Social e Ambiental - RGSA, São Paulo, v. 11, n. 1, p. 90-104, jan./abr. 2017. 